\title{
The Planning of Teaching in the Context of Lesson Study: Research Findings
}

\author{
Eurydice-Maria Kanellopoulou ${ }^{1} \&$ Maria Darra ${ }^{2}$ \\ ${ }^{1}$ Teacher of Secondary Education (M.Ed.), Greece \\ ${ }^{2}$ Department of Primary School Education, University of the Aegean, Greece \\ Correspondence: Eurydice-Maria Kanellopoulou, Teacher of Secondary Education (M.Ed.), Greece. E-mail: \\ evikanell@gmail.com
}

Received: September 26, 2017

Accepted: November 7, 2017

Online Published: January 26, 2018

doi:10.5539/ies.v11n2p67

URL: https://doi.org/10.5539/ies.v11n2p67

\begin{abstract}
The main purpose of the present study is to examine the attitudes, perceptions and experiences of the teachers participating in the planning of teaching in the context of the Lesson Study. The present work, which is part of a wider research effort, followed a mixed methodological planning for reasons of triangulation. The survey was conducted from February 12 to April 1, 2016, in the second grade of the Secondary Education School in the prefecture of Attica and a total of 31 students, the Director as well as the four teachers of literature of the school unit participated in it. The results of the survey show that the participating teachers were positively influenced by the detailed planning and preparation of the research lesson, gaining useful experience and valuable knowledge during the implementation of the Lesson Study phases. In addition to that, their attitudes and perceptions about the meetings and workshops carried out within Lesson Study were positively evaluated.
\end{abstract}

Keywords: lesson study, planning of teaching, research lesson, secondary education, teachers' perceptions and attitudes

\section{Introduction}

The upgrading of the Greek educational system is a continuous demand of teachers and modern Greek society. The Lesson Study is an innovation in the field of education that has been successfully tested in many developed nations and its exploitation can make a positive contribution to improving education and making it effective (Perry \& Lewis, 2008).

In particular, judging from the review of the relevant references for the implementation of Lesson Study, the results are as follows:

- Transferring a successful teaching method to another country is feasible by adapting it to its educational culture (Cowen, 2006). Also, the introduction of educational innovation from another country can be a great success when educational interaction between countries is promoted (Phillips, 2006).

- Appropriate planning of the teaching, as well as its proper implementation, by enhancing the active role of teachers and students, contributes to the improvement of the educational process (Sofos \& Darra, 2014).

- In addition to that, research lessons can contribute to the effective implementation of educational policy in the classroom and to the upgrading of the education system (Lewis \& Tsuchida, 1997).

- Equal participation of teachers is considered a necessary condition for the success of the Lesson Study (Lewis \& Hurd, 2011). Also, in the Lesson Study, teachers actively participate as researchers (Rekalidou, Karadimitriou, \& Moumoulidou, 2014), in order to achieve a common goal, in a voluntary and not coercive way (Cook, \& Friend, 1991).

- Open-ended questions facilitate the free expression of participants' views on teaching, as well as preparatory and reflective meetings (Creswell, 2011).

- Lesson Study develops cooperation and communication among teachers (Chong \& Kong, 2012) and strengthens friendly interpersonal relationships.

- The Lesson Study for young and inexperienced teachers contributes to their professional development 
significantly (Archer, Pope, Onion, \& Wake, 2013).

- In particular, with this teaching method, teachers' participation and fruitful exchange of ideas are fostered within the working groups (Kambouridis, 2002).

- At the meetings of the Lesson Study working groups, honest relationships of mutual respect and appreciation are developed. Through the Lesson Study and the teaching of the research lesson, teachers do not hesitate to be exposed and to collaborate with their colleagues (Thiessen, 1993).

- The implementation of the Lesson Study presupposes the provision of infrastructure in a school unit, as well as the adaptation and modification of the program timetable, so as to facilitate the participating teachers without losing their teaching hours and to sustain its normal functioning (Anthopoulou, 1999). Collaborative planning of educational practices enhances teachers' interest in their profession, upgrading the quality of their work (Athanasoula-Reppa, 1999).

From all the above it is concluded that a) the use and appropriate implementation of the Lesson Study in a school unit is conducive to the promotion and development of the educational process and b) the lack of relevant research to illustrate the attitudes, perceptions and experiences of teachers in the context of Lesson Study implementation in Greek educational reality. The present work aims to cover this lack of research.

\section{Teaching Planning in the Context of Lesson Study: A Theoretical Approach}

Lesson Study is a process of improving teaching and learning, not only for students but also for teachers, which originally appeared in Japan (Giannakidou, Yoftsali, \& Tziora, 2013).

In its context, the participating teachers collaborate collectively for their professional development by creating learning communities through the design of a research lesson (Penteri, Karadimitriou, \& Rekalidou, 2013). Its teaching and observation is used to collect data on student learning.

The use of these data for feedback and redesign of teaching, contributes decisively to the improvement of teachers' teaching skills (Stepanek, Appel, Leong, Mangan, \& Mitchell, 2007).

Lesson Study is based on the pedagogical theory of learning of social constructivism (Rekalidou, Karadimitriou, \& Moumoulidou, 2013), which adopts the social character of knowledge (Anderson \& Dron, 2011). According to this theory, pre-existing knowledge of the pupils serves to build the new one, with the guidance and encouragement of teachers, who creatively apply reflection in their teaching (Sofos \& Darra, 2015).

\subsection{Lesson Study Phases}

For Lesson Study implementation, teachers devote 10-15 hours in 3-4 weeks (Fernandez, 2002). Lesson Study process, as shown in the diagram below (Stepanek, Appel, Leong, Mangan, \& Mitchell, 2007), includes the following phases:

\section{Setting goals}

II. Planning the research lesson

III. Teaching, observing and data collecting of the research lesson

IV. Evaluation - Feedback and re-teaching

V. Reflection - Formulation and sharing final results 
Process of Lesson Study

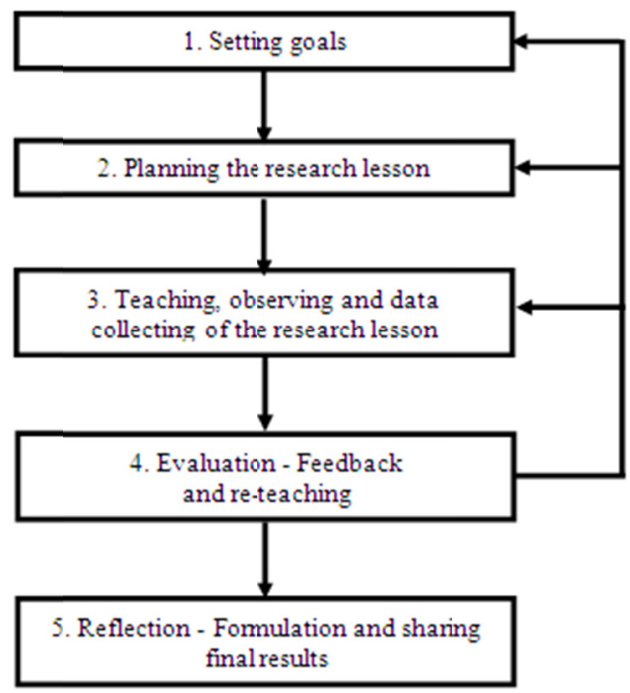

Figure 1. Phases of the lesson study (Adaptation by Stepanek et al., 2007)

\section{Setting goals}

In the first phase of Lesson Study process, teachers work together to form a small group of 3-6 individuals (Cerbin, \& Kopp, 2011) in order to examine the objectives that their pupils should achieve. By studying the curriculum, they detect gaps between these future goals and the existing reality.

They look for an important subject for students, which seems interesting or could cause learning difficulties, or a new module that has recently been added to the curriculum. They explore, through brainstorming, in the context of a fruitful dialogue, strategies and teaching methods that will direct their students to gain knowledge on the specific subject. Teachers, by justifying their selected didactic approaches, set the foundations for proper planning of goals (Rekalidou, 2012; Lewis, \& Hurd, 2011).

\section{Planning the research lesson}

Teachers choose a module from the curriculum that is directly related to the topic they choose in the previous phase and cooperatively plan a research lesson in detail. This lesson will accomplish the goals they set for pupils' learning and development and especially not what they will learn, but mainly how they will learn (Cerbin \& Kopp, 2006). At this stage, teachers spend enough time to organize their teaching together. They shape the learning pathway to follow, predict the expected questions of their students (Verhoef \& Tall, 2011) and prepare a data collecting plan. During these meetings, observations and suggestions for improvement of the teaching plan are made. At the end of this phase, a written analytical teaching plan emerges, which the group will implement in the classroom (Rekalidou, 2012; Lewis \& Hurd, 2011).

\section{Teaching, observing and data collecting of the research lesson}

The research lesson is conducted, with one member of the group teaching and the rest observing and collecting data on the teaching and learning of the students (Shaun, 2014). This collection can be made by various means. Notes and observations recording, as well as students' oral and written answers, are used in the next phase that is the evaluation-feedback (Rekalidou, 2012; Stepanek et al., 2007).

\section{Evaluation-Feedback and re-teaching}

In the context of evaluation, teachers thoroughly analyze the data gathered during the lesson. The purpose of evaluation is not to critique the way the specific teacher teaches this lesson. Evaluation-feedback aims to generate valuable lessons for class and module planning, and therefore to improve student and teacher learning.

Applying improvements can mark the end of the Lesson Study phases or re-planning the same lesson again or conducting next Lessons Study cycles with a different subject (Easton, 2009). If research lesson repeating is appropriate in the context of evaluation-feedback, due to incorrect students' oral or written answers at their worksheets, re-planning is carried out in another student group of the same class by another teacher of the same group (Rekalidou, 2012). 


\section{Reflection-Formulation and sharing final results}

Lesson Study process is completed by reflection and formulation, recording and publication of the final results (Hiebert, Gallimore, \& Stigler, 2002). Reflection reinforces the collectivity of teachers who review the research lesson (Polemi-Todoulou, 2010).

The written formulation of the results is carried out through interactive discussion and joint analysis of the data and results of the research lesson. These results can be used and exploited by other groups of teachers who are interested in implementing the Lesson Study.

\section{Purpose and Research Questions}

The main purpose of this study is to examine the attitudes, perceptions and experiences of the teachers involved in teaching planning in the context of the Lesson Study. In particular, this study aims to examine: a. Teachers' perceptions about Lesson Study implementation planning, b. Teachers' views on meetings-workshops that took place in the context of the Lesson Study, and c. Attitudes and perspectives of teachers on the steps and processes of the Lesson Study cycle.

The individual research questions that the research will attempt to answer are:

1st: What are the perceptions of teachers about Lesson Study implementation planning?

2nd: What are the teachers' views regarding the meetings-workshops that took place in the context of the Lesson Study?

3rd: What are the teachers' attitudes and perceptions on the steps and processes of Lesson Study cycle?

\section{The Research}

\subsection{The Sample}

In this specific survey, sample selection was deliberate and not accidental, as it is done in quantitative surveys, which aim at generalizing their results.

In this research work, the criterion of the sample's selection was the voluntary participation of teachers, who can contribute to understanding the impact of Lesson Study on improving the function of the school. This research requires direct access of the researcher to the environment of a school unit. Choosing the school in which the researcher works, has contributed decisively to its realization.

The survey was conducted at the General Lyceum of Eastern Attica from February 12 to April 1, 2016, in the subject of Literature with the permission of the relevant school advisors and the school principal. The director and, initially, all the school's four scholars were involved, but then one left. The two classes of the 2nd Lyceum were also involved, the first consisting of sixteen (16) students as a team of experimentation and the second of fifteen (15) as a control group. Teachers' meetings were held, with few exceptions, on a regular weekly basis within the school hours and their participation was voluntary.

\subsection{The Method}

The present work, which is part of a wider research effort, followed a mixed methodological planning for triangulation purposes. As data-gathering tools, transcripts of the participants teachers in Lesson Study and teachings (traditional and research lesson) were used. Also, calendars that were filled in at the time of Lesson Study implementation by the facilitator and the group recorder, as well as the protocols for planning, observation, reflection and revision of the research lesson were used as data. Sources also included student work as well as questionnaires completed by pupils. The questionnaires also generated quantitative data, which were used to enhance in-depth analysis of the quality data. The existence of the above-mentioned different data sources contributed through triangulation to the validation of research results, which give it credibility and validity (Robson, 2010).

\subsection{Collection of Research Data}

\section{Meetings and teachings}

The meetings and teachings which took place during Lesson Study were recorded for the fullest collection of data and the best documentation of the research.

At the introductory meeting, the participating teachers were thoroughly informed by the researcher about the content and phases of the Lesson Study. Modern Greek Literature was unanimously chosen for this study, which presents some peculiarities and is the only lesson that is taught by all the school's scholars. It was also agreed to teach a specific poem and its traditional teaching should be conducted before the beginning of the Lesson Study 
so that the teacher is not influenced by the application of the new way of teaching. An indicative timetable for the implementation of traditional teaching and subsequent meetings was also established. The six meetings that followed, following traditional teaching, were devoted to the detailed design of the research lesson. After its teaching, the last meeting provided important data for evaluation-feedback and reflection of the research lesson.

\section{Meeting calendars}

Meeting calendars were another tool of this research, as they were recorded as important elements of the Lesson Study meetings as soon as they were finished. These figures were particularly useful, especially when there was a reasonable time between meetings and there was danger of them being forgotten and ignored. In the present study, two types of calendars were drawn from Stepanek et al. (2007).

In the first type, the diary was completed by a member of the group and the second by the facilitator. These two team members changed at each meeting. The two questionnaires had common fields related to the objectives and to the main points of the meeting and were differentiated in the other fields.

In particular, each member whose turn was to hold the diary, recorded data on the content of the meeting, teaching, pupil learning and the short and long-term goals of the group. Steps were also recorded for planning the next meeting and its content was determined.

In the corresponding calendar, the facilitator initially mentioned his actions, which contributed to the effective participation of the team members. He then noted any problems that arose at the meeting, and how to deal with them. He mentioned the degree of participation of all members of the group, as well as the possible strengthening of their cooperation.

III. Planning protocol of the research lesson

The planning protocol for the research lesson used in this research is derived from Stepanek et al. (2007) and took place in four stages.

In the first, the research topic was identified according to the students' cognitive level, their educational needs, the teachers' learning needs as well as the gaps or shortcomings found in the curriculum. In the second stage, the module and the research lesson were selected. The course was chosen according to the student's knowledge and needs. In the third stage the objectives of the course were determined. At the last stage, the Lesson Study team jointly developed a detailed plan of the research lesson. With this plan, teachers using pre-existing knowledge of students anticipated possible questions or difficulties in understanding the course and planned activities for student assessment.

\section{Research lesson review protocol}

The research lesson review protocol was necessary for the completeness of the research. It was adopted from Stepanek et al. (2007) and was implemented in four steps. In the first step of collection and data analysis, the participating teachers worked out the tools of observation and reflection of the research lesson. They also considered their notes, as well as the answers of the students, both oral and written. In data analysis, they identified the extent to which the learning objectives and the teaching points helped or made it difficult for students to achieve their cognitive goals. In identifying necessary changes, they jointly decided which parts of the teaching were successful and which need changes and interventions for improvement. In the final step of revising the lesson plan, teachers have developed a revised and detailed plan for teaching the research lesson according to their observations.

\section{The teachers' questionnaire}

In the present study, a questionnaire was distributed to the participating teachers during the reflection phase. This questionnaire is formulated by Stepanek et al. (2007) and was partly modified to meet the needs of this research. This questionnaire included mostly closed and open questions.

The closed-ended questions included three axes. The first axis contained eight (8) criteria, the second eleven (11) and the third six (6). The answers to closed-ended questions, according to the Likert scale, ranged from absolute disagreement to absolute agreement. In five open-ended questions, teachers freely expressed their views.

On the first axis, there were eight criteria related to the Lesson Study informational meetings. Understanding of Lesson Study objectives, assimilation of the material, adequacy of the available time, and usefulness of the meetings were explored. In the second, there were eleven criteria that recorded the views of the participating teachers for the Lesson Study cycle. The cooperation between team members, planning, benefits and success of the research lesson were explored. 
On the third axis, there were six criteria focusing on implementation and learning from Lesson Study.

Teachers' benefits from their involvement in Lesson Study and the ability to exploit their positive effects on their teaching were examined. In the five open-ended questions, teachers were asked to identify the strengths and weaknesses of the Lesson Study, to suggest ways to improve it, and to express their views on the contribution of Lesson Study to cultivating collaborative climate and improving the learning process.

\section{Results of the Survey}

Recorded meetings and teachings, of the traditional and research lesson were transcribed in digital form as text files (Creswell, 2011). Subsequently, these files were imported into the Atlas.ti program $\tau$ o analyze their content by editing and encoding them, i.e. dividing the texts into parts by giving them a title. These titles were grouped and combined with other research data sources they were categorized into different fields, which are directly related to the research questions. The results and main findings of the research are as follows:

\subsection{Teachers' Reports on Implementation Planning of Lesson Study}

Detailed planning of Lesson Study is a basic prerequisite for its successful implementation and has dominated the meetings of the group of the participating teachers.

As shown in the following snippets from the first meeting, the initial planning steps are recorded:

Professor A: Fine. Let me ask something else now. Let's have a little talk about our meetings. Let's do a scheduling. When can we talk, because we have to set goals here, as we have seen. That is to say, we must all realize these phases.

Professor C: What do you suggest?

Professor A: I do not know. Now, as I have seen the program, so as not to lose teaching hours, we can say we can work on Fridays if you like, for two-hours, 5th and 6th hour,

Professor B: Probably so.

At the second meeting, planning protocol was strictly observed for the definition of the research theme, its module, course and objectives, as recorded:

Professor B: Good morning colleagues. Well, following the procedure analyzed by our colleague in our first meeting, today we will have to define our research theme and define the long-term and short-term goals. To define the research topic, we need to look at the difficulties faced by students either in understanding some concepts or in the learning process. What do you say?

Professor A: Yes, okay.

Professor B: Well, for example, let us first define our subject. Let's look at some difficulties that are about poetry, poetry analysis, poetry is usually more difficult for our students than in prose.

Professor A: Sure. This happens. Yes.

At the third meeting, planning was further enriched, as shown in the following passage:

Professor A: At this stage, we need to plan together in detail and organize the teaching in such a way that the objectives of learning and the development of pupils are achieved, not just what they will learn, but rather how they will learn. Of course we should also check whether our goals have been achieved through appropriate activities.

By setting the learning goals, as we have recorded them, and set in our previous meeting, we aim to develop students' critical and synthetic thinking, as well as our own professional development. We also seek to increase pupils' involvement in educational practice, and to activate their prior knowledge in building new knowledge.

Professor B: Fine, of course.

Professor A: Now, in the detailed planning of the research lesson, we must anticipate the expected questions and queries from our students and prepare a data collection plan. At the end of this phase we will have prepared a written analytical teaching plan, which one of our team will be asked to apply to the classroom. At our next meetings we can make comments, suggestions for improving the teaching plan.

At the fourth meeting, the design improved even further, as can be seen from the text of the following transcript:

Professor D: Today we will make comments and suggestions for improving the teaching plan that we thought of yesterday. Let me remind you that it will be held next Friday for a continuous two hours at the 3rd and 4th hour. Ok? 
Professor A: Okay, okay.

Professor B: Yes, yes.

And at the fifth meeting, design completion captured most of the discussion:

Professor A: And in this meeting we will deal with the analytical teaching plan. In its detailed presentation, we need to check if the plan fully meets the goals we have set, if all the questions are clear, if we identify possible difficulties-questions that students may have. And in this case we have to decide how to deal with them.

Professor D: Let's get started.

At the meeting after the research lesson, planning was evaluated and the team reached useful conclusions using its review protocol:

Professor D: Colleagues, judging from the written answers of the students in the control group and in the experimental group, which has just finished teaching, I think we can make useful conclusions for planning the lesson and therefore improving learning of pupils and teachers.

Now, colleagues in the evaluation-feedback we need to analyze the data we collected during the course. Let me remind you that we do not criticize the teacher.

Professor B: Right.

Professor D: Let's get started. Dear colleague, I think you have to start, since you have taught the lesson. And then we will make our observations.

The team may decide on modifications concerning, for example, the method, the order of questions, means or other parameters of the teaching. We make an assessment of planning, implementation, means, methods, results. And we will certainly make better suggestions.

Teachers' reports on the detailed planning of the research lesson are depicted in the chart below by Atlas. 


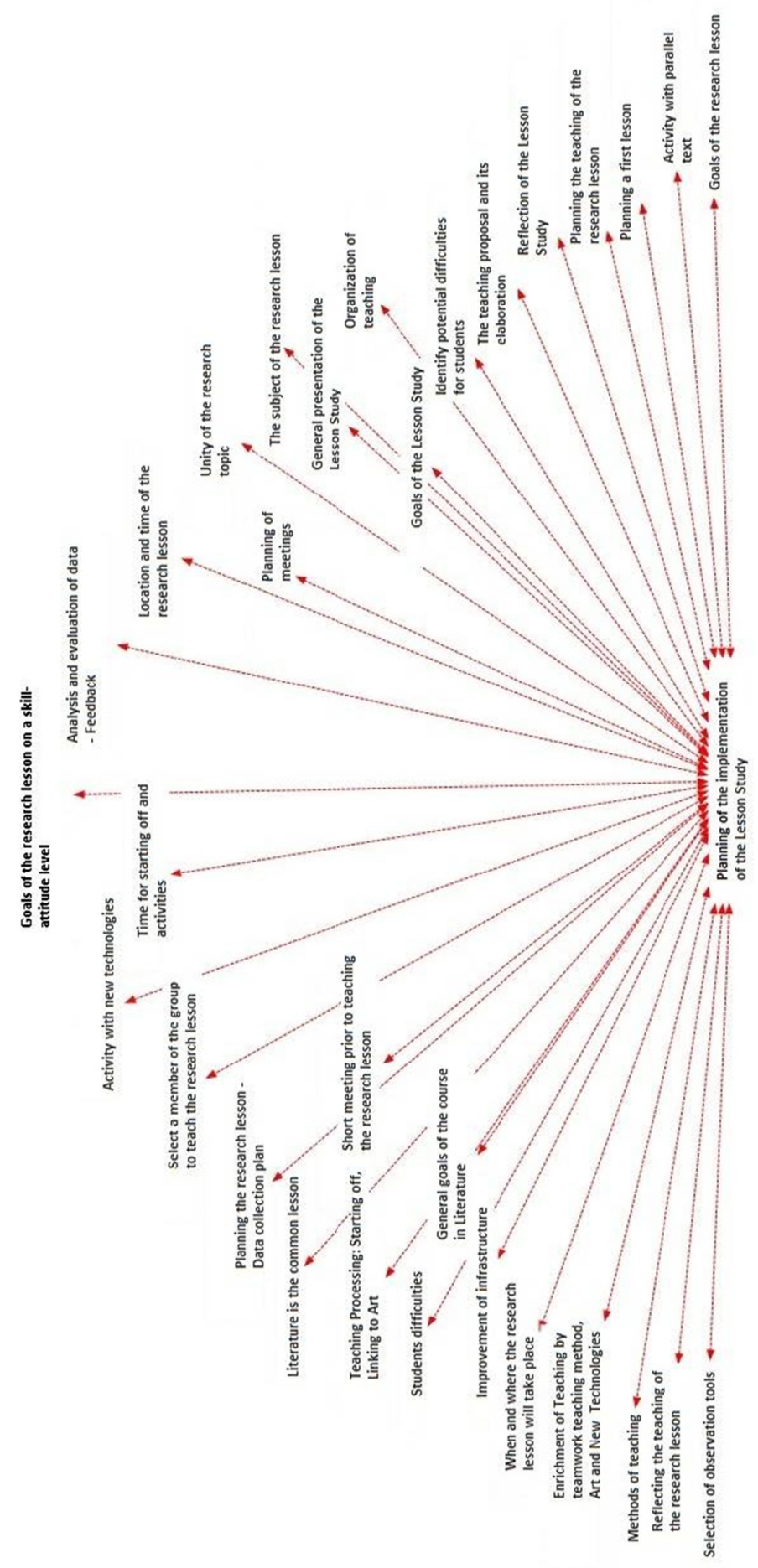

Figure 2. Tree chart illustrating teachers' references regarding planning implementation of Lesson Study

5.2 Teachers' Views Regarding the First Axis of the Teachers' Questionnaire Entitled: Meetings-Lesson Study Workshops

The initial planning was also recorded in the first axis of the teachers' questionnaire entitled: Meetings-Lesson Study Workshops 
This axis included eight criteria, which are as follows:

In the first criterion: I understood the objectives and the process of the Lesson Study before starting the course of the Lesson Study

$100 \%$ responded that it fully agrees.

In the second criterion: The material that was given helped me understand the Lesson Study more $100 \%$ also responded that it totally agrees.

In the third: Introductory activities helped me understand the Lesson Study more 50\% replied that they agreed and the remaining $50 \%$ replied that they fully agreed.

In the fourth: The time I worked with my colleagues in the Lesson Study group helped me understand more the Lesson Study

$50 \%$ responded that they agreed and the remaining $50 \%$ responded that they fully agreed.

In the fifth: The facilities I have been given helped me understand the Lesson Study more

$100 \%$ responded that it fully agrees.

In the sixth: The workshops gave me enough time to understand the Lesson Study more

$50 \%$ replied that they agreed and the remaining $50 \%$ replied that they fully agreed.

In the seventh: The workshops were made at a convenient time for me

$50 \%$ replied that they agreed and the remaining $50 \%$ replied that they fully agreed.

In the eighth: Workshops were useful

$50 \%$ replied that they agreed and the remaining $50 \%$ replied that they fully agreed.

Teachers' responses to the initial design of the research lesson are illustrated in the following bar graph. 


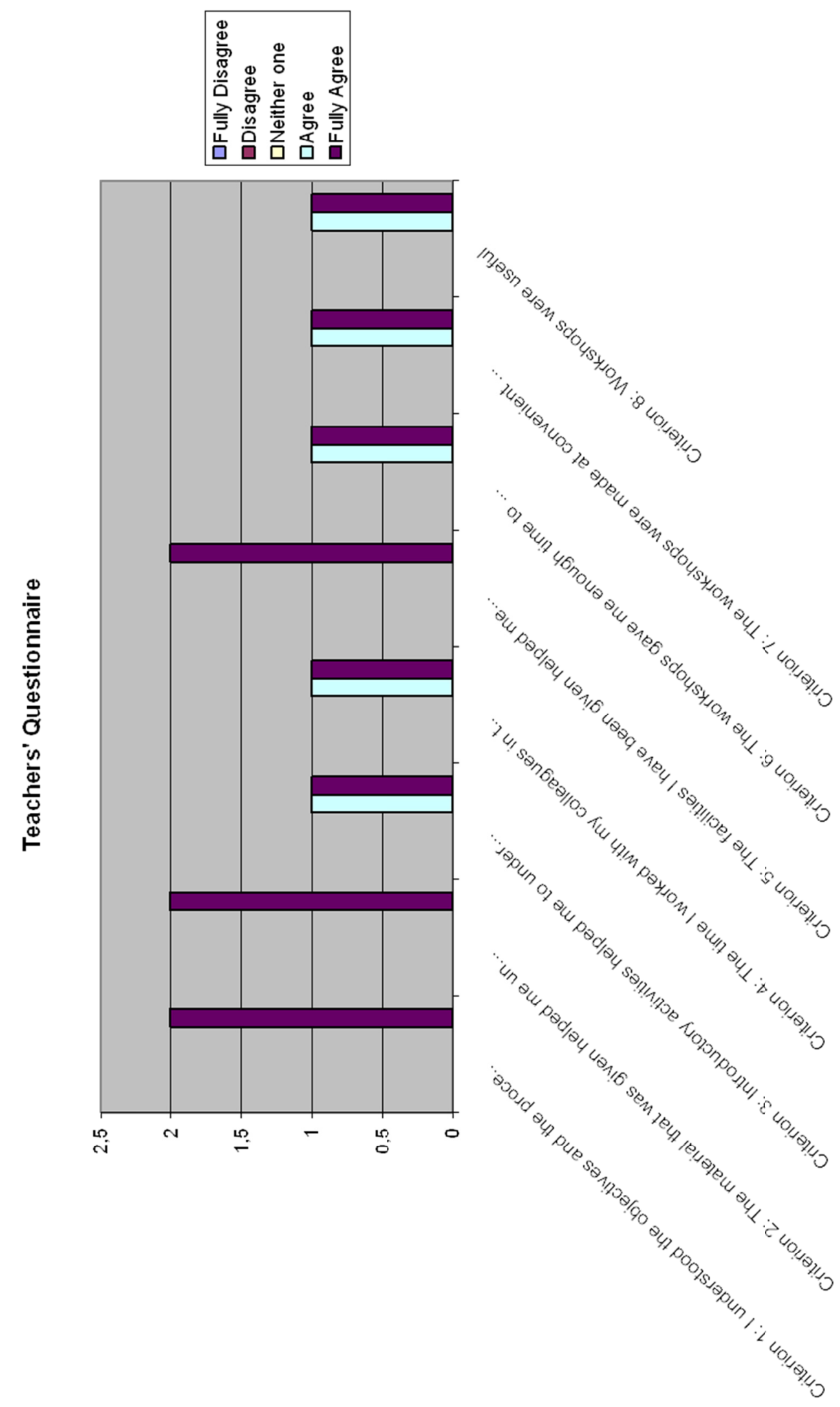

Figure 3. Teacher answers on the initial planning of the Lesson Study 


\subsection{Teacher Perceptions in Relation to the Steps and Processes of the Lesson Study Cycle}

The second axis of the teachers' questionnaire was entitled: The Lesson Study cycle included eleven (11) criteria also related to planning of the Lesson Study, which are as follows:

In the first criterion: Meetings during the Lesson Study were made in a convenient time for me

$50 \%$ replied that they agreed and the remaining $50 \%$ replied that they fully agreed.

In the second criterion: I had the opportunity to attend all the meetings during the Lesson Study

$100 \%$ responded that it fully agrees.

In the third: The Lesson Study team has worked effectively to plan the research lesson.

$50 \%$ replied that they agreed and the remaining $50 \%$ responded that they fully agreed.

In the fourth: The research lesson matched our primary goal

$50 \%$ replied that they agreed and the remaining $50 \%$ replied that they fully agreed.

In the fifth: The Lesson Study team used textbooks, research, or other external information to help planning the lesson

$100 \%$ responded that it fully agrees

In the sixth: We had the opportunity during the course of the Lesson Study to solve the problems of the research lesson in order to promote our expectations of students' understanding

$100 \%$ responded that it fully agrees.

In the seventh: The development of the research lesson has allowed me to increase my knowledge of teaching content

$50 \%$ replied that they agreed and the remaining $50 \%$ replied that they fully agreed.

In the eighth: The development of the research lesson allowed me to understand the way students think better and / or the difficulties of my teaching content

$100 \%$ responded that it fully agrees

In the ninth: Observing learners' learning way of thinking during teaching or research was an important learning experience

$50 \%$ replied that they agreed and the remaining $50 \%$ replied that they fully agreed.

In the tenth: I think our research lesson was a success

$100 \%$ responded that it fully agrees.

In the eleventh: Participating in a Lesson Study Cycle was a valuable professional development activity

$50 \%$ replied that they agreed and the remaining $50 \%$ replied that they fully agreed.

Teachers' answers on the steps and processes of the Lesson Study cycle are illustrated in the following bar graph. 


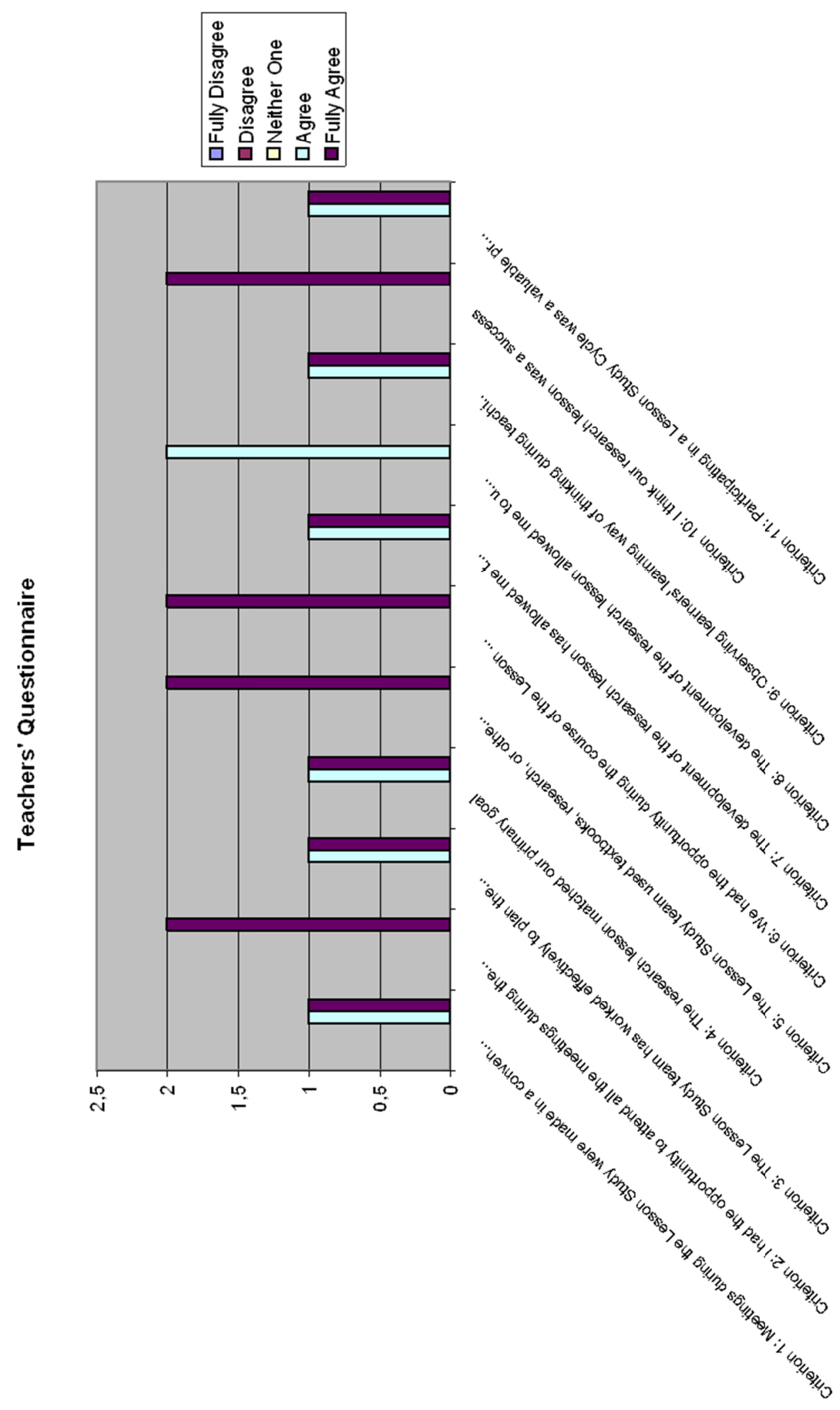

Figure 4. Teachers' response bar graph on course steps and processes of lesson study's cycle 


\section{Discussion}

From the overall view of individual findings, there are specific conclusions regarding the teaching planning based on the Lesson Study approach, which are described in more detail below.

With regard to teachers' perceptions of the design in implementing the Lesson Study, the findings of the research showed that the detailed planning of the research lesson, preoccupied the participating teachers in all their meetings. The enrichment, improvement, integration and strict adherence to the project planning protocol by the team, reveals that all its members had realized the great importance of planning for the successful outcome of the project. In addition, in the post-research lesson meeting, where useful conclusions were drawn, evaluation-feedback mainly focused on lesson planning. This finding, which also complies with the relative references (Britain, 2004), highlights the great importance of lesson /course planning as a criterion for its effectiveness. In addition, this result means that teaching planning, in its broad sense, is a methodology that supports educators to make informed and pedagogically credible decisions about how to proceed with organizing teaching of a course or program by effectively making advantage of the appropriate resources.

As far as the perceptions and experiences of the teachers regarding the Workshops-Meetings that took place in the context of the Lesson Study are concerned, it is concluded that: a. All agree completely regarding the understanding of the objectives and the process of the Lesson Study before the beginning of the Course Study, and that the material they were given helped them understand the Lesson Study more fully. b. Half said that they fully agree and the other half that they agree on the usefulness of the introductory activities, in the collaboration with their colleagues in the team and the workshops in the fullest understanding of the Lesson Study. This finding shows that all the teachers were well informed on the Lesson Study process and that the participation of teachers in a climate of mutual respect, cohabitation and fellowship is also important for the success of the Lesson Study. These assumptions are also recorded in the research of Lewis and Hurd (2011). In addition, this result highlights the contribution of Lesson Study to the reflection and the development of a professional interaction and cooperation, to the adoption by teachers of a research attitude about their practice (Hargreaves \& Fullan, 1995), as well as in enhancing the professionalism of all participants through the understanding and recognition of the complexity of teaching, sharing common practical knowledge, exchanging information and teaching techniques and focusing on them (Peterson, 2000). In this sense, the planning of teaching emerges as a critical pedagogical frame of reference and consequently the terms associated with it are often terms such as "critical awareness", "empowerment", "qualitative development", "self-action", "autonomy", "change" and “improvement" (Altrichter \& Specht, 1998).

In relation to the teachers' attitudes and experiences regarding the steps and processes of the Lesson Study cycle, it follows that: a. all agree completely regarding their ability to attend all meetings during the Lesson Study, that the Lesson Study Group has used manuals, research, or other external information to assist in the planning of the lesson, that they had the opportunity during the lesson study cycle to solve the problems of the research lesson in order to help students' expectation of understanding, that the development of the research lesson has enabled them to better understand the Student thoughts and / or the difficulties of their teaching content and that they believe that our research lesson was successful and $b$. half said that they fully agree and the other half that they agree that the meetings during the Lesson Study were made in a convenient time for them, that the Lesson Study team worked effectively on the planning of the research lesson, that the research lesson matched with their primary objective, that the development of the research lesson helped them increase their knowledge of the content of their teaching, the observation of the students' learning and that the way of thinking during the teaching of the research lesson was an important learning experience and that their participation in a lesson study cycle was a valuable professional development activity.

This result matches with the elements of the relevant references, according to which teachers working in a communicative and reflective context interpret their practice and the practice of other participants and are in constant readiness to redefine their goals (Carr \& Kemmis, 1997). In addition, the teacher through participation in a group of colleagues can better achieve the goal of improving the effectiveness of teaching if $s /$ he relies on reflection and feedback s/he can get from his/her team of colleagues, which provides him/her with a support environment in which everyone feels that they are learning and constantly improving (Barkley, \& Cohn, 1999). At the same time, this result shows that the main advantages attributed to the use of the teaching planning are firstly the ability to provide the teacher with a reflection on the context of a metacognitive process that directs his/her pedagogical and didactic choices and feedbacks the educational process by putting an end to it in mechanically repetitive operations, and secondly, the possibility for the teacher to have effective plans, as good practices, to be revised, shared and reused in future teaching situations (Polkas \& Touloumis, 2012). 


\section{Conclusions and Suggestions}

From the results of the research carried out in the framework of this paper, useful conclusions and findings from the implementation of the Lesson Study in the particular unit are drawn. In particular, it appears that the participating teachers were positively influenced by the detailed planning and preparation of the research lesson, gaining useful experience and valuable knowledge during the implementation of the Lesson Study. In addition, their attitudes and perceptions and experiences about the meetings and workshops carried out within Lesson Study have been positively evaluated.

Despite the positive results with regard to the planning of teaching based on the Lesson Study approach, there are some limitations that should be mentioned. The sample of the survey, 31 students, was a relatively small one. Using a larger sample would enhance the credibility of the research. There were time constraints on the implementation of the research program, which did not allow for longer duration. Finally, as in each survey, participants, and in this case students, may not have been completely honest in their responses to their impressions, linking the conduct of research with the exam process.

From the work constraints, the proposals for further research, which could focus on the following axes, arise. The present study was conducted only in the teaching of the Literature course in students of a secondary school. Future studies could examine the effectiveness of Lesson Study in teaching other subject matter as well in pupils of younger and/or older classes. Finally, future work could use a combination of quantitative and qualitative approaches, and in particular to conduct personal interviews with students, teachers and school advisors.

The next phase could be to set up a more extensive program of interventions, which, over a longer period, will also include teaching in more subjects. The implementation of such a program in a larger group of pupils and with the participation of a larger number of teachers and the comparative study of the data is expected to provide a more complete picture of the effectiveness of the Lesson Study in relation to other parameters of the didactic-learning process, such as exploring its contribution to the motivation of pupils, the development of more positive attitudes of pupils towards school and learning as a result of its implementation, and others.

\section{References}

Altrichter, H., \& Specht, W. (1998). Quality assurance and quality development in education. International approaches and parameters as applying to the austrian school system. In J. Solomon (Ed.), Trends in evaluation of education systems: School (self-)evaluation and decentralization. Athens: Pedagogical Institute.

Anthopoulou, S.-S. (1999). Counseling and motivation of educational staff. In A. Athanasoula-Reppa, S.-S. Anthopoulou, S. Katsoulakis, \& G. Mavrogiorgo (Eds.), Management of Educational Units: Human Resources Management (Vol. 2, pp. 187-228). Patra: HOU.

Archer, R., Pope, S., Onion, A., \& Wake, G. (2013). Working group report: Lesson study in research and CPD in mathematics education. Retrieved from http://www.bsrlm.org.uk/lps/ip33-2/BSRLM-IP-33-2-C

Athanasoula-Reppa, A. (1999). Communication within the educational organization. In A. Athanasoula-Reppa, S-S. Anthopoulou, S. Katsoulakis, \& G. Mavrogiorgos (Eds.), Management of Educational Units: Human Resources Management (Vol. 2, pp. 137-185). Patra: HOU.

Barkley, S., \& Cohn, R. (1999). Professional growth plans offer alternative to teacher checklists. The School Administrator Web Edition. Retrieved from http://www.aasa.org

Britain, S. (2004). A Review of Learning Design: Concept, Specifications and Tools. A Report for the JISC E-learning Pedagogy Programme. Retrieved from http://www.jisc.ac.uk/media/documents/programmes/elearningpedagogy/learningdesigntoolsfinalreport.pdf

Carr, W., \& Kemmis, S. (1997). For a Critical Educational Theory: Education, Knowledge and Action Research (Translation: A. Lambraki-Paganou, E. Blinga, and K. Rodiadou-Albani). Athens: Code.

Cerbin, B., \& Kopp, B. (2006). Lesson study as a model for building pedagogical Knowledge and improving teaching. International Journal of Teaching and Learning in Higher Education, 18(3), 250-257.

Cerbin, B., \& Kopp, B. (2011). Lesson study project overview. Retrieved from http://www.uwlax.edu/sotl/lsp/overview.htm

Chong, W., \& Kong, C. (2012). Teacher collaborative learning and teacher self-efficacy: The case of Lesson Study. The Journal of Experimental Education, 80, 263-283. https://doi.org/10.1080/00220973.2011.596854 
Cook, L., \& Friend, M. (1991). Principles for the practice of collaboration in schools. Preventing School Failure, 35(4), 6-9. https://doi.org/10.1080/1045988X.1991.9944251

Cowen, R. (2006). Acting comparatively upon the educational world: Puzzles and Possibilities. Oxford Review of Education, 32(5), 561-573. https://doi.org/10.1080/03054980600976155

Creswell, J. (2011). Research in education. Planning, conducting and evaluating quantitative and qualitative research. Translation: N. Kouvarakos. Edited by: C. Tsorbatzoudis. Athens: Ion.

Easton, L. (2009). An Introduction to Lesson Study. Florida and the Islands Regional Comprehensive Center. Day One. November \& December, 1-35.

Fernandez, C. (2002). Learning from Japanese approaches to professional development: the case of lesson study. Journal of Teachers Education, 53(5), 393-405. https://doi.org/10.1177/002248702237394

Giannakidou, E., Yoftsali, K., \& Tziora, E. (2013). The Reflective Action of Candidate Teachers in Applying an Adapted Version of the Lesson Study Model. Research in Education Hellenic Journal of Research in Education, 1, 30-58. Alexandroupolis.

Hargreaves, A., \& Fullan, M. (1995). The evolution of teachers. Athens: Patakis.

Hiebert, J., Gallimore, R., \& Stigler, J. (2002). A Knowledge base for the teaching profession: What would it look like and how can we get one? Educational Researcher, 31(5), 3-15.

Kambouridis, G. (2002). Organization and Administration of School Units. Athens: Kleidarithmos.

Lewis, C., \& Hurd, J. (2011). Lesson Study step by step. How Teacher Learning Communities Improve Instruction. Portsmouth, $\mathrm{NH}$, USA.

Lewis, C., \& Tsuchida, I. (1997). Planned educational change in Japan: the case of elementary science instruction. Journal of Education Policy, 12(5), 313-331. https://doi.org/10.1080/0268093970120502

Penteri, E., Karadimitriou, K., \& Rekalidou, G. (2013). Involvement of future and active teachers in an advanced model of teacher education. Conference of the Network of Practice Exercises in the Department of Early Childhood Education, on "Improving the Education of Future Teachers in Crisis of Institutions: Proposals, Applications". Alexandroupolis, 26-28 September.

Perry, R., \& Lewis, C. (2008). What is successful adaptation of lesson study in the US? J Educ Change. https://doi.org/10.1007/s10833-008-9069-7

Peterson, K. D. (2000). Teacher evaluation: A comprehensive guide to new directions and practices. Thousand Oaks, CA: Corwin Press.

Phillips, D. (2006). Investigating policy attraction in education. Oxford Review of Education, 32(5), 551-559. https://doi.org/10.1080/03054980600976098

Polemi-Todoulou, M. (2010). The Systemic Approach-Key to a New Educational Planning. Metologist, Systemic Society of Northern Greece, 18, 1-27.

Polkas, L., \& Touloumis, K. (2012). Study on the planning, development and implementation of educational activities for the teaching of ancient Greek language and literature in Secondary Education. Thessaloniki: Publications Center of the Greek Language.

Rekalidou, G. (2012). Improving teaching. The case of Lesson Study. Pedagogy-Theory and Practice, 5, 98-109.

Rekalidou, G., Karadimitriou, K., \& Moumoulidou M. (2013). Basic components of the implementation of the Lesson Study model in the practical training of four-year students of TEEP-DTU: collaboration, reflection, feedback, observation. Conference of the Network of Practice Exercises in the Department of Early Childhood Education, on "Improving the Education of Future Teachers in Crisis of Institutions: Proposals, Applications". Alexandroupolis, 26-28 September.

Rekalidou, G., Karadimitriou, K., \& Moumoulidou, M. (2014). Implementation of Lesson Study with students. Collaboration, reflection and feedback. Research in education. DTU. Retrieved from http://www.ereunastinekpaideusi.gr

Robson, C. (2010). Real-world research. Translation: V. Dalakou, \& K. Vassilikou. Edited by: K. Michalopoulou, \& F. Kalyva. Athens: Gutenberg

Shaun, A. (2014). Perfect CPD Teacher-Led. U.K., Independent Thinking Press.

Sofos, A., \& Darra, M. (2014). Utilization of learning planning in the educational process: Exploring the 
perceptions of teachers in the Templates of Experimental Schools. Proceedings of 1st Congress of DEPPS.

Sofos, A., \& Darra, M. (2015). Models of Learning Planning: Comparative and Interpretative Assessment. Education Sciences, 1, 66-83. University of Crete, Rethymnon.

Stepanek, J., Appel, G., Leong, M., Turner Mangan, M., \& Mitchell, M. (2007). Leading Lesson Study. A practical guide for teachers and facilitators. California, USA.

Thiessen, D. (1993). The evolution of teachers based on the classroom. In Hargreaves, A., \& Fullan, M (Eds.), The evolution of teachers. Translation: P. Hatzipantelis. Athens: Pataki.

Verhoef, N., \& Tall, D. (2011). Lesson Study: The effect on teachers' professional development. Proceedings of the 35th Conference of the International Group for the Psychology of Mathematics Education, 1, pp. XXX-YYY. Ankara, Turkey: PME 35. Retrieved from http://doc.utwente.nl/80245/1/RR_verhoef.pdf

\section{Copyrights}

Copyright for this article is retained by the author(s), with first publication rights granted to the journal.

This is an open-access article distributed under the terms and conditions of the Creative Commons Attribution license (http://creativecommons.org/licenses/by/4.0/). 